\title{
Friction welding of austenitic steel fasteners
}

\author{
Viktor Shchepkin ${ }^{1, *}$ and Yuri Poletaev ${ }^{1}$ \\ ${ }^{1}$ Don State Technical University, Gagarin square, 1, Rostov-on-Don, 344003, Russia
}

\begin{abstract}
The purpose of this work is to increase the efficiency of manufacturing non-standard fasteners. In the course of the work, the technology of friction welding bolts, which ensures the formation of highquality welded joins, from steels of grades $14 \mathrm{X} 17 \mathrm{H} 2$ and $12 \mathrm{X} 18 \mathrm{H} 10 \mathrm{~T}$ was experimentally investigated and developed.
\end{abstract}

\section{Introduction}

Large enterprises manufacture a large range of fastening bolts for various purposes and sizes (with threads from M16 to M64; length up to $200 \mathrm{~mm}$ ), from carbon and alloy steels. Bolts are made by turning from hexagonal or round blanks, according to the technology: cutting the blank; heat treatment; shot blasting (sandblasting) processing; bolt turning; machining the bolt head for a hexagon. This technology is characterized by a high technological cost, since a large portion of the metal is converted into shavings. The solution to this problem is possible through the development of a resource-saving friction welding technology.

When using friction welding, the productivity of the process of obtaining a welded joint increase significantly, highly qualified operators are not required, and electricity is saved; the specified welding method is environmentally friendly in comparison with electric arc methods [1-5].

The bolt manufacturing technology using friction welding includes the following basic operations: cutting blanks (head, rod); welding of workpieces; heat treatment (if necessary); shot blasting (sandblasting) processing; turning the bolt.

In connection with the foregoing, the purpose of this work is to experimentally study the process and develop a technology for friction welding of bolts from steels $14 \mathrm{X} 17 \mathrm{H} 2$ and $12 \mathrm{X} 18 \mathrm{H} 10 \mathrm{~T}$, which ensures the formation of the structure and properties of welded joints that meet the requirements of regulatory documents.

In general, the theoretical foundations of friction welding have been developed [6-12]. Friction welding occurs in a solid state when exposed to heat generated by friction of the surfaces of the welded product. The work spent on overcoming the frictional forces turns into heat, which causes the joint to heat up to a temperature of $950-1300{ }^{\circ} \mathrm{C}$. The process of forming a welded joint is completed by forging: an increased welding force is applied to the heated, but already stationary parts for some time. After forging, natural cooling of the welded joint occurs. One of the most important advantages of the friction welding method is the high quality of the resulting welded joints [6-8,11-15]. The quality of the welded

\footnotetext{
${ }^{*}$ Corresponding author: shepkinviktor@rabmler.ru
} 
joint made by friction welding depends on the completeness of the processes occurring on the contact surfaces: removal of contaminants; wear and tear of oxide films, as well as nearsurface layers of workpieces; plastic flow of metal; hardening and softening of surface layers; rapid heating and cooling, causing structural - phase transformations; mass transfer of metal from one workpiece to another and the formation between the contact surfaces of solid "wedges" formed from cut microroughnesses and tending to grow due to metal transfer [14-15]. To implement these theoretical provisions, the following tasks were set and solved: the choice of the optimal form of preparation of workpiece surfaces for welding was determined; the choice of welding process parameters were experimentally substantiated; the effect of heat treatment on the structure and properties of welded joints was studied; quality assessment of welded joints was carried out according to the results of non-destructive and destructive testing.

\section{Research technique and equipment}

The choice of the optimal form of preparing the edges for welding was carried out on the basis of comparative results of the complexity of manufacturing with the possibility of using a wider range of parameters of the welding mode, in which a high-quality welded joint is formed.

Several variants of the form of preparation of blanks for the rod and bolt head have been investigated in the work (Fig. 1). When preparing the edges according to the option (Fig. 1a), the welded joint is formed with a gently curved weld line. The widest heat-affected zone (HAZ) is formed on the rod due to heat removal predominantly in one direction. The amount of upset is equal to the amount of shortening of the rod.

The welded joint according to the option (Fig.1b) has a joint line in the form of a curve with a concavity into the head blank. The width of the HAZ from the weld line is approximately the same in both directions. This is due to the fact that the heat in the rod blank is concentrated before the completion of the heating phase, due to the tapered surface of the rod. The extent of upset is equal to the total loss of length of the rod due the proctss.

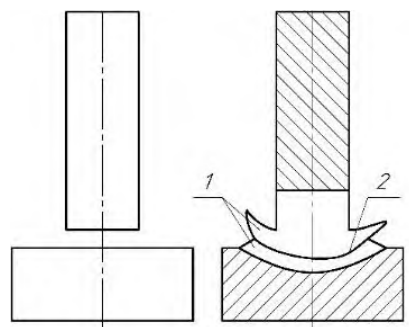

a)

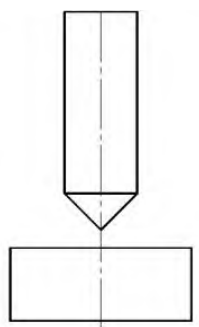

b)

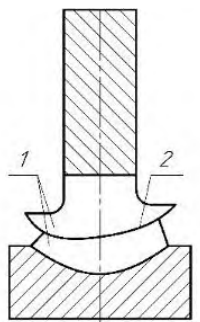

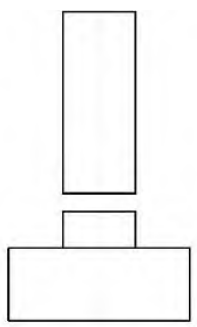

c)

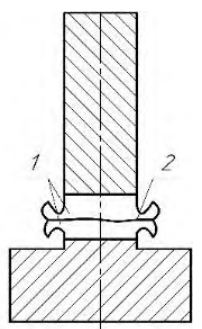

Fig. 1. Variants of preparation of edges for welding and realised welded joints: 1 - heat-affected zone; 2 - seizure line. Other parts are defined in the text.

When preparing the edges according to the option (Fig.1c), the welded joint has an almost straight weld line. HAZs are the same in width, which indicates a uniform heat distribution. The amount of upset is made up of both the shortening of the rod blank and the head blank. Of the options considered, the one that provides the least cost for preparing the edges for welding while allowing for the widest range of welding parameters, where a highquality welded joint may be obtained, is option (Fig. 1a) 
The testing and selection of the optimal parameters for the process (heating pressure $\mathrm{P}_{\mathrm{n}}$; forging pressure $-\mathrm{P}_{\mathrm{fp}} ; \mathrm{t}$ - welding time; with a constant parameter - rotation speed $\mathrm{V}=$ $1000 \mathrm{rpm}$ ) were carried out on analogs of fasteners, which were round blanks of a certain length and a range of diameters (fig. 2).

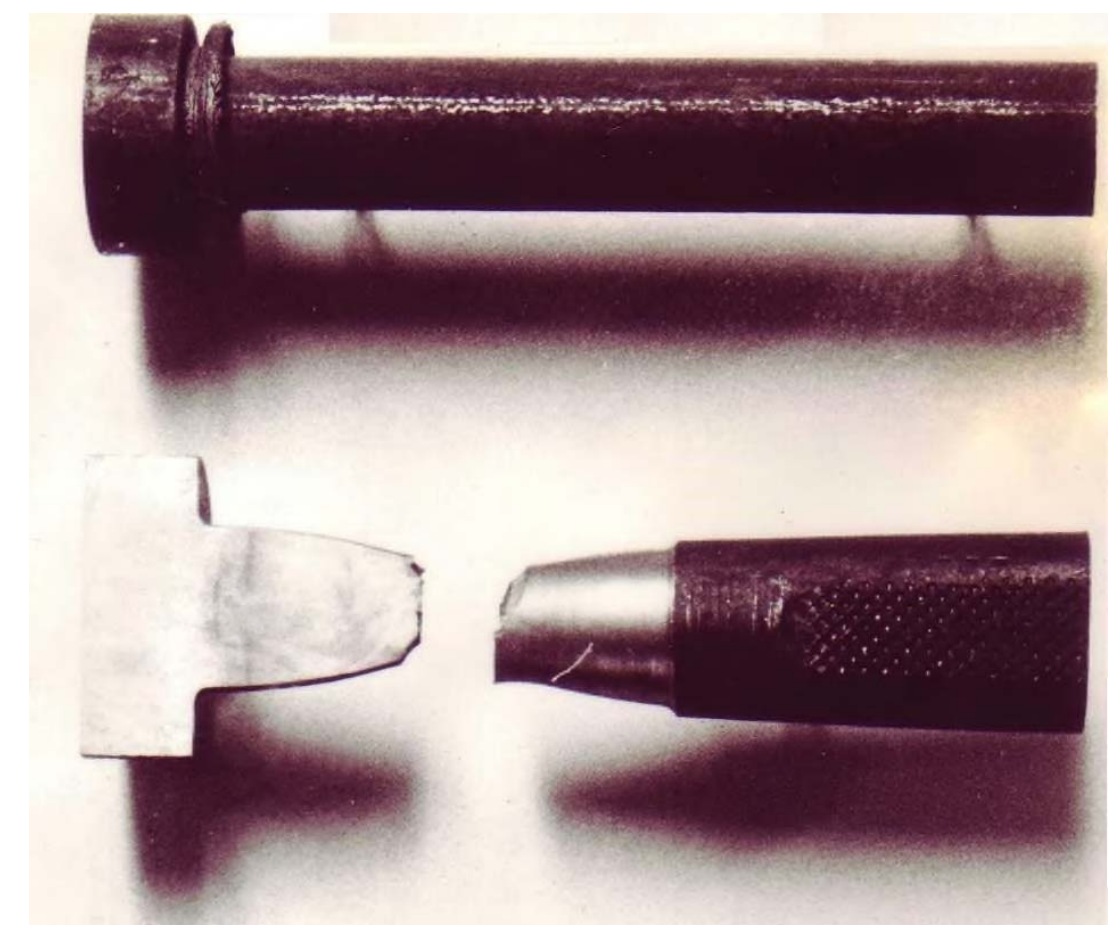

Fig. 2. Analogs of bolts

Welding work was performed on a PST-20 machine. When working out the welding modes, the need for heat treatment of welded joints was identified, as was the rest time required time between the end of welding and the beginning of heat treatment.

The quality of welded joints was assessed based on the results of non-destructive (external inspection and ultrasonic testing) and destructive (tensile tests, impact strength, bending, hardness, microhardness and metallographic studies) verification. External examination revealed possible defects, irregularities in the form of the joint and determined the size of the burr. Internal unacceptable defects were revealed by ultrasonic testing. The resulting welded joints were subjected to mechanical tests after appropriate mechanical treatment. Metallographic studies were performed on macrosections cut in the area of the welded joint in the longitudinal direction. On macrosections, the length of the HAZ was measured, the hardness determined by the Vickers method, and defects were identified. The assessment of the effect of heat treatment on the distribution of hardness, which characterizes the mechanical properties, was carried out over the section of the welded joint. The microhardness $\mathrm{H} \mu$ was measured on a PMT-3 device (the load on the indenter was $50 \mathrm{~g})$.

Measurements were performed on microsections cut from the corresponding macrosections. The grain size was determined using a metallographic microscope and regulatory documents. Based on the results of the analysis of the data obtained, the corresponding parameters of the friction welding process were refined. 


\section{Research results and their discussion}

Friction welding of bolt analogs was carried out in compliance with the following process parameters: specific heating pressure -19.5 to $29.4 \mathrm{MPa}$; specific pressure of forging -68.5 $\mathrm{MPa}$; sediment -3.4 to $4.2 \mathrm{~mm}$; heating time -8 sec.; rotation speed $-1000 \mathrm{rpm}$.

The tensile test was carried out directly on the analog bolts, after deburring and turning the rod with head undercut. The analogs were tested both in the initial state after welding and after heat treatment - improvement (tempering $630-650{ }^{\circ} \mathrm{C}$ ). Ultimate tensile strength sv, at $20^{\circ} \mathrm{C}$, is: $617-627 \mathrm{MPa}(12 \mathrm{X} 18 \mathrm{H} 10 \mathrm{~T})$ and $835-843 \mathrm{MPa}(14 \mathrm{X} 17 \mathrm{H} 2)$. When testing for impact strength, an incision was made along the butt line of the welded joint. At the same time, KCV was: $52.4 \mathrm{~J} / \mathrm{m} 2(12 \mathrm{X} 18 \mathrm{H} 10 \mathrm{~T})$ and $48.3 \mathrm{~J} / \mathrm{m} 2(14 \mathrm{X} 17 \mathrm{H} 2)$. It should be noted that in the initial state after welding, both steels had an insufficient bend angle, which indicates the need for heat treatment. It is recommended to combine post-weld heat treatment with heat treatment to improve the properties of the base metal.

Analysis of the macrostructure of welded joints showed that the structure of individual sections of joints in the state after welding represents alternating zones with different etchability, dispersion and hardness. A similar structure is typical for metal subjected to various thermal and deformation effects during welding. On samples of steel 12X18H10T and $14 \mathrm{X} 17 \mathrm{H} 2$ in the state after heat treatment, zones with different etching and dispersion were not revealed, which indicates the formation of a homogeneous structure and properties, confirmed by hardness measurements (Fig. 3 and Fig. 4).

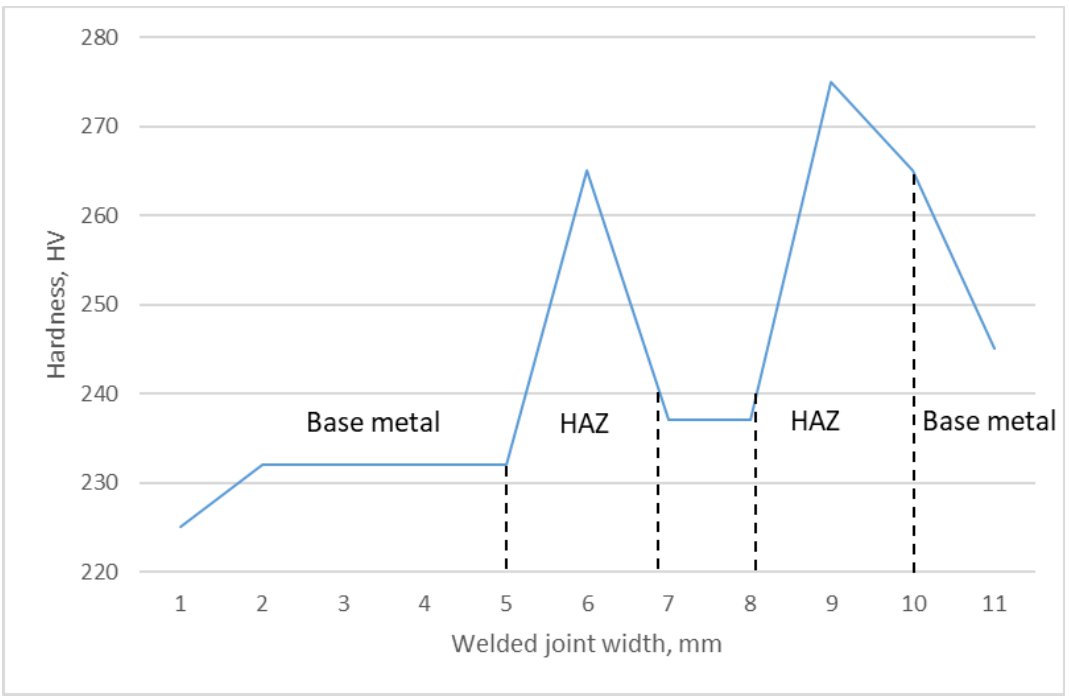

Fig. 3. Distribution of hardness over the section of a welded joint made of steel 12X18H10T

It should be noted that during friction welding, the metal experiences not only a high thermal effect (heating to a temperature of $1100-1300^{\circ} \mathrm{C}$ ), but also deformation. For this reason, welded joints made of $14 \mathrm{Kh} 17 \mathrm{~N} 2$ steel in the initial state after welding have a quenched structure (martensite) with a maximum hardness: HV570. Heat treatment forms a homogeneous structure and lowers the hardness of the welded joint to $203-228 \mathrm{HV}$. 


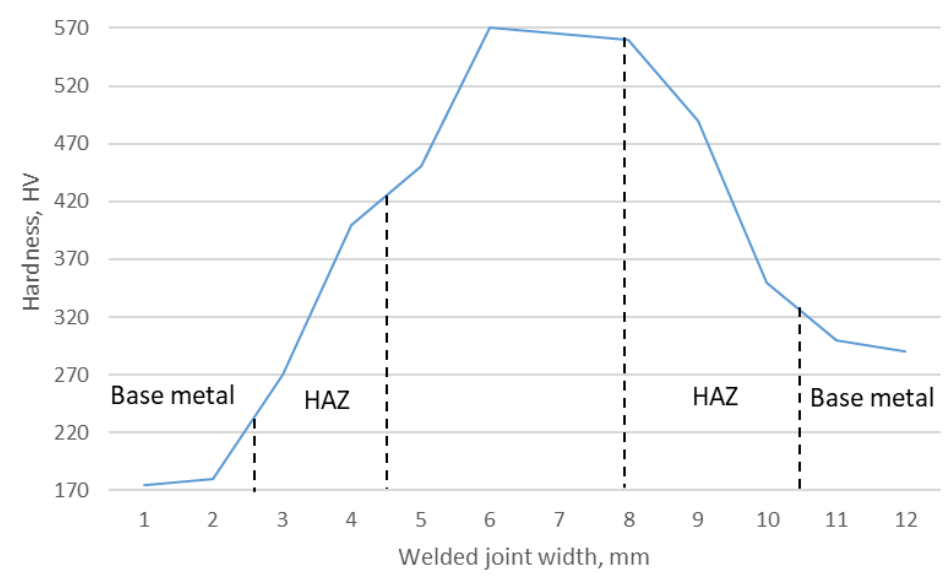

Fig. 4. Distribution of hardness over the section of welded joint made of steel 14X17N2

Analysis of the microstructure indicates the formation of a high-quality welded joint without cracks. In Fig. 5 shows the microstructure of the welded joint of steel 12X18H10T in the initial state after welding.

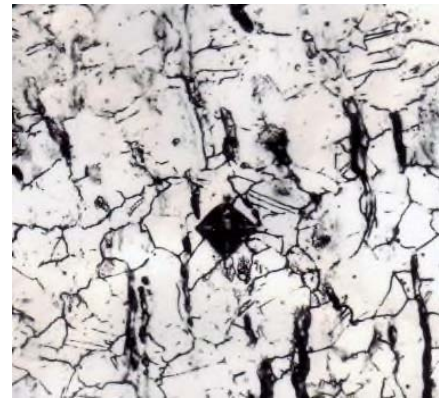

a)

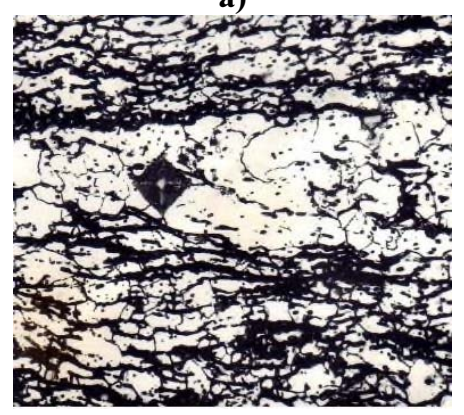

c)

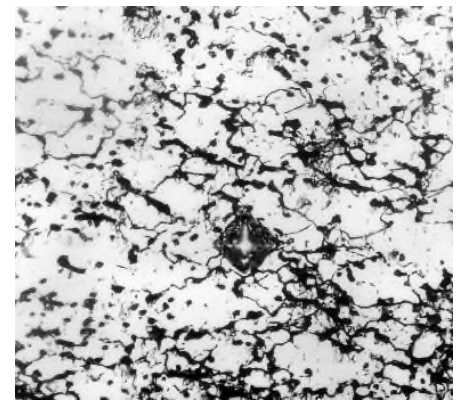

b)

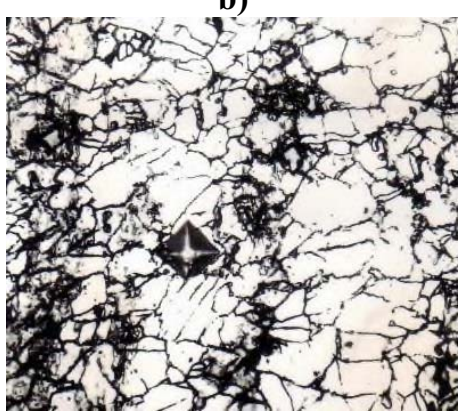

d)

Fig. 5. Microstructure: base metal (a), HAZ (b), butt zone (c), base metal (d) of the welded joint of steel $12 \mathrm{X} 18 \mathrm{H} 10 \mathrm{~T}$ without heat treatment, $\mathrm{x} 300$.

The base metal (Figure 5a) is austenite and ferrite with a rolled texture, microhardness $176 \mathrm{H \mu}$. The heat-affected zone (Fig.5b) is a recrystallized austenite-ferrite structure with a microhardness of $159 \mathrm{H \mu}$. The butt zone (Fig.5c) has a pronounced fiber yield, which can 
significantly reduce the properties, especially the fatigue strength of the welded joint. The base metal (Fig.5d) also has an austenitic-ferritic structure with a low fiber yield, microhardness $168 \mathrm{H} \mu$.

It can be seen that the thermal deformation effect of the welding process contributed to the formation of a noticeable structural and mechanical inhomogeneity. The base metal has an austenitic-ferritic structure, with a grain size of $7-8$ points and a hardness up to $275 \mathrm{HV}$ (see Fig. 4).

Figure 6 shows the change in the microstructure over the section of a welded joint made of steel $14 \mathrm{X} 17 \mathrm{H} 2$. After heat treatment - tempering $630-650{ }^{\circ} \mathrm{C}$. The structure over the entire cross section is martensite with 203-228 N $\mu$ (Fig. 6 a-c).

The base metal of a rod of smaller diameter retains a clearly defined structure (Fig. 6e) of ferrite, which can also be traced in the zone of thermal deformation (Fig. 6b). The joint zone has a pronounced fiber yield (Fig. 6c), the microhardness decreases to $181 \mathrm{~N} \mu$.

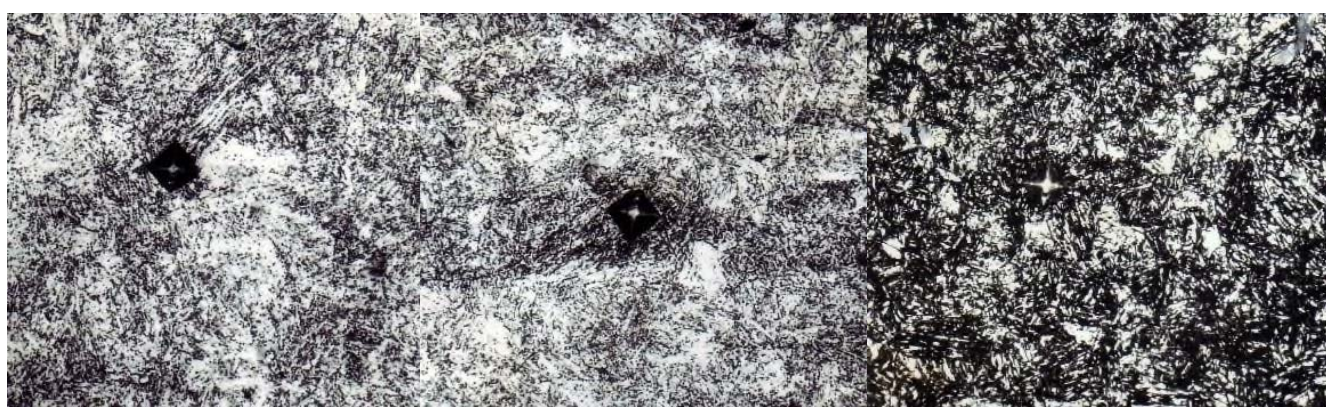

a)

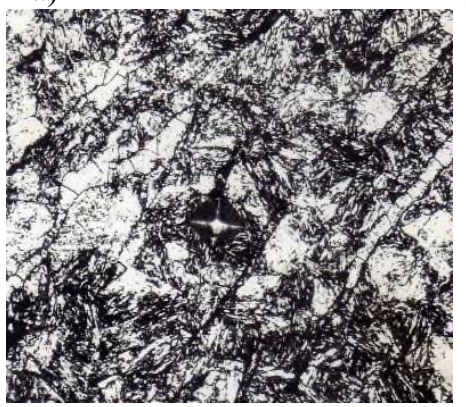

d) b)

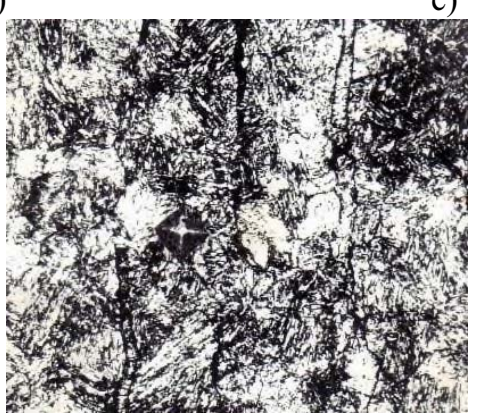

e)

Fig. 6. The microstructure of the welded joint of steel $14 \mathrm{X} 17 \mathrm{H} 2$ in the initial state after welding: a base metal; b - HAZ; c - joint zone; after heat treatment: d - HAZ; e - base metal, x300.

\section{Conclusions}

1. The positive results of the performed studies substantiate the feasibility of using the friction welding method for the manufacture of fasteners.

2. The choice of the optimal shape of the welded joint of fasteners has been determined.

3 . The optimal parameters of friction welding of $12 \mathrm{X} 18 \mathrm{H} 10 \mathrm{~T}$ and $14 \mathrm{X} 17 \mathrm{H} 2$ steel bolts on the PST-20 machine have been determined. The quality assessment of welded joints was carried out according to the results of non-destructive and destructive testing.

4. The effect of heat treatment on the structure and properties of welded joints has been studied. It is shown that the required uniformity of the structure and mechanical properties 
of welded joints of steels $12 \mathrm{X} 18 \mathrm{H} 10 \mathrm{~T}$ and $14 \mathrm{X} 17 \mathrm{H} 2$ is formed after heat treatment (improvement).

5. The technology of friction welding has been developed, which makes it possible to manufacture bolts that meet the requirements of regulatory documents.

6. Introduction of the developed technology into production will allow the enterprise to obtain savings in materials, energy resources, cutting tools and reduce the technological cost of manufacturing bolts.

\section{References}

1. M. Kimura, K. Ohara, M. Kusaka, K. Kaizu, K. Hayashida, Journal of Advanced Joining Processes, 2, Article 100028 (2020)

2. L. Bingwang, S. Qingyu, Y. Likun, L. Chunyan, J. Pan, G. Chen, Journal of Manufacturing Processes, 56, 643-655 (2020)

3. V. Deepesh, A. V. Purushothaman, S. Muthukumaran, D. Sastikumar, Materials Today: Proceedings, 27(3), 2286-2292 (2020)

4. R. Nikiforov, A. Medvedev, E. Tarasenko, A. Vairis, JOURNAL OF Engineering Science and Technology Review, 8, 50-53 (2015)

5. Y. Poletaev, V. Poletaev, V. Shchepkin, Svarochnoe Proizvodstvo, 6, 44-49 (2020)

6. M. R. Kelly, S. R. Schmid, D. C. Adams, J. Fletcher, R. Heard, Journal of Manufacturing Processes, 39, 26-39 (2019)

7. V. Deepesh, A. V. Purushothaman, S. Muthukumaran, D. Sastikumar, Materials Today: Proceedings, 27(3), 2218-2224 (2020)

8. P. Geng, G. Qin, J. Zhou, Z. Zou, International Journal of Mechanical Sciences, 152, 420-431 (2019)

9. Y. Poletaev, V. Poletaev, V. Shchepkin, Svarochnoe Proizvodstvo, 7, 13-18 (2018) doi: 10.1016/j.ijmecsci.2019.01.014

10. K. Srinivasan, S. Senthil Kumaran, Materials Today: Proceedings, 22(4), 2266-2273 (2020) doi: 10.1016/j.matpr.2020.03.347

11. I. Bhamji, M. Preuss, L. P. Threadgill, R. J. Moat, A. C. Addison, M. J. Peel, Materials Science and Engineering: A, 528, 680-690 (2010)

12. H. Ma, G. Qin, P. Geng, F. Li, X. Meng, B. Fu, Journal of Materials Processing Technology, 227, 24-33 (2016) doi: 10.1016/j.jmatprotec.2015.08.004

13. S. S. Kumar, N. Murugan, K. K. Ramachandran, International Journal of Refractory Metals and Hard Materials, 58, 196-205 (2016)

14. R. Paventhan, P. R. Lakshminarayanan, V. Balasubramanian, Journal of Iron and Steel Research, International, 19, 66-71 (2012)

15. R. Winiczenko, M. Kaczorowski, Materials \& Design, 34, 444-451 (2012) doi: 10.1016/j.matdes.2011.08.038 